\title{
Experimental Study on the Mechanical Properties of FRP Bars by Hybridizing with Steel Wires
}

\author{
Ji-Hyun Hwang, Dong-Woo Seo*, Ki-Tae Park, Young-Jun You \\ Structural Engineering Research Division, Korea Institute of Construction Technology, Goyang, Korea \\ Email: jhhwang@kict.re.kr, ${ }^{*}$ dwseo@kict.re.kr, ktpark@kict.re.kr, vivou@kict.re.kr
}

Received 8 April 2014; revised 8 May 2014; accepted 16 May 2014

Copyright (C) 2014 by authors and Scientific Research Publishing Inc. This work is licensed under the Creative Commons Attribution International License (CC BY). http://creativecommons.org/licenses/by/4.0/

(c) (i) Open Access

\begin{abstract}
Many studies on fiber reinforced polymer composite bars, as a substitute for reinforcing bars, have been conducted to solve corrosion of steel in reinforced concrete structures since 1960s'. However, FRP Bars have a lower elastic modulus than steel rebar as a structural component of concrete structures. Material properties with brittleness fracture and low elastic modulus can be improved by combining cheaper steel than carbon or aramid fibers. In this study, prototypes of FRP Bars with inserted steel wires (i.e., "FRP Hybrid Bars") were developed and their tensile performance was compared depending on the proportion and diameter of steel. The FRP Hybrid Bars were made by dividing them into D13 and D16 according to the diameter and proportion of inserted wires: GFRPs were combined with wires having different diameters of $0.5 \mathrm{~mm}, 1.0 \mathrm{~mm}$, and $2.0 \mathrm{~mm}$ in the proportion of $10 \%, 30 \%, 50 \%$, and $70 \%$, respectively. As a result of tensile tests, the elastic modulus of FRP Hybrid Bars were improved as $20 \%-190 \%$ in comparison with the fully GFRP Bars.
\end{abstract}

\section{Keywords}

Fiber-Reinforced Polymer (FRP), FRP Hybrid Bar, Tensile Test, Steel Wire

\section{Introduction}

Many studies on fiber reinforced polymer composite bars (i.e., FRP Bars), as a substitute for reinforcing bars, have been conducted to solve corrosion of steel in reinforced concrete structures since 1960s' [1] [2].

There have been, however, few cases of application of FRP Bars in construction structures in Korea, although

\footnotetext{
*Corresponding author.
}

How to cite this paper: Hwang, J.-H., Seo, D.-W., Park, K.-T. and You, Y.-J. (2014) Experimental Study on the Mechanical Properties of FRP Bars by Hybridizing with Steel Wires. Engineering, 6, 365-373. 
the FRP Bars have many merits, including high tensile strength, corrosion resistance, and non-magnetic property. The reasons why they are not popular as a construction material is as follows: 1) higher price than the existing reinforced bars; 2) brittleness characteristics different from plastic behaviors of reinforced bars; 3) low elastic modulus.

Material properties with brittleness and low elastic modulus can be improved by combining with materials that have higher elastic modulus. Jones et al. have performed experiments on the combined composites of carbon/carbon, glass/glass, aramid/carbon, glass/carbon fibers, and then obtained pseudo-ductile behaviors when small amounts of fibers with low stretch were well distributed [3]. In these cases, however, there was a problem of increasing the unit price of products [4].

Korea Institute of Construction Technology (KICT [5]) in Korea is recently conducting studies on development of Glass-Fiber-Reinforced Polymer (GFRP) Bars that compensates for these shortcomings and the low economical benefits [6]. Material properties with brittleness fracture and low elastic modulus can be improved by combining with cheaper material of steel than carbon or aramid fibers.

Increasing elastic modulus by inserting steel as core material into GFRP, hybridized bars can be developed as a substitute of reinforced bars with merits that can strengthen durability in the condition of chloride corrosion such as the environment exposed to the ocean.

Three kinds of reinforced bars have currently developed at KICT as follows: 1) those with inserted D9 reinforced bars as core material and externally braided with GFRP; 2) those with inserted D4 steel wires as core material and externally braided with GFRPs; 3) those with uniformly distributed D2 steel wires and FRPs. All three kinds of reinforced bars showed higher elastic modulus than the existing FRP Bars did and also plastic behaviors different from the existing GFRP Bars (more details can be found in [6]).

In this study, prototypes of GFRP Bars with inserted steel wires (FRP Hybrid Bars) were mainly considered and their performance was tested as a function of the proportion and diameter of steel. In detail, the effects of the proportion of GFRPs and steel as well as combining methods were compared and analyzed through tensile tests to verify the validity of developed prototypes.

Through these processes, the development of optimized FRP Hybrid Bars was in attempt to finally apply to marine and harbor structures to replace the steel rebars.

\section{Development of "FRP Hybrid Bars"}

"FRP Hybrid Bars" developed through this study were proposed to improve the tensile performance of the existing GFRP Bars by inserted a core material of steel into GFRPs [6]. FRP Hybrid Bars with high performance, in which GFRP fibers were combined with the varying proportion of steel wires. Several diameter sizes of the wire were applied to develop the prototypes of FRP Hybrid Bars in this study.

Materials used to develop FRP Hybrid Bars are as shown in Table 1. Generally, resins in which two the unsaturated polyesters were mixed with DION-9100 and HETRON-922 for FRP. SE1200 of the ECR class that was fiber reinforced material providing fast impregnation, high mechanical strength, and corrosion resistance mixed into the resin. Steel wires were distributed as metal reinforced material into the FRP core. Finally, polyamide nylon fibers were used to simulate a shape of deformer to bond strength between the FRP Hybrid Bar and concrete.

Table 2 presents the list of specimens for tensile test. Specimen names, quantities, manufacturing methods of high performance FRP Hybrid Bars proposed in this study described in Table 1. Figure 1 shows the schematic

Table 1. Material properties used in development of FRP Hybrid Bars.

\begin{tabular}{cccc}
\hline Properties/Uses & Product names & Tensile strength (MPa) & Elastic coefficient (MPa) \\
\hline Resin & DION-9100 & 79 & 3216 \\
Resin & HETRON 922 & 86 & 3170 \\
Tensile strengthening & SE1200 & 2600 & 81,000 \\
Tensile strengthening & Steel wires (KS D3510 C) & 1170 & 190,000 \\
Shape of deformer & Nylon fibers & 70 & 75,000 \\
\hline
\end{tabular}




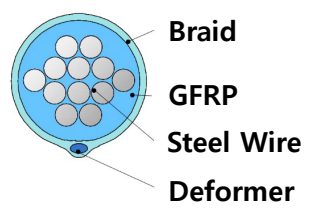

(a)

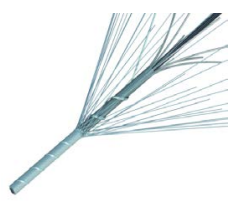

(b)

Figure 1. Schematic details of cross section (a) and configuration of manufacturing processes (b) for FRP Hybrid Bars.

Table 2. Type of FRP Hybrid Bars.

\begin{tabular}{cccc}
\hline Case & Specimen name & Quantity & Remarks \\
\hline 1 & GBN-D13 & 3 & D13/ None/GFRP/Braid \\
2 & GBSD0.5-68-D13 & 7 & D13/0.5 mm wire $10 \% /$ GFRP/Braid \\
3 & GBSD1-17-D13 & 7 & D13/1.0 mm wire $10 \% /$ GFRP/Braid \\
4 & GBSD2-4-D13 & 7 & D13/2.0 mm wire $10 \% /$ GFRP/Braid \\
5 & GBSD2-13-D13 & 7 & D13/2.0 mm wire 30\%/GFRP/Braid \\
6 & GBSD2-21-D13 & 7 & D13/2.0 mm wire 50\%/GFRP/Braid \\
7 & GBSD2-30-D13 & 7 & D13/2.0 mm wire 70\%/GFRP/Braid \\
8 & GBSD0.5-102-D16 & 6 & D16/0.5 mm wire 10\%/GFRP/Braid \\
9 & GBSD1-26-D16 & 6 & D16/1.0 mm wire 10\%/GFRP/Braid \\
10 & GBSD2-6-D16 & 6 & D16/2.0 mm wire 10\%/GFRP/Braid \\
11 & GBSD2-19-D16 & 6 & D16/2.0 mm wire 30\%/GFRP/Braid \\
12 & GBSD2-32-D16 & 6 & D16/2.0 mm wire 50\%/GFRP/Braid \\
13 & GBSD2-45-D16 & 6 & D16/2.0 mm wire 70\%/GFRP/Braid \\
\hline
\end{tabular}

configuration of cross section and manufacturing processes of high performance FRP Hybrid Bars.

As shown in Table 2, FRP Hybrid Bars were designed by dividing into D13 and D16 as an outer diameter and the diameter and proportion of inserted wires: GFRPs were combined with steel wires of $0.5 \mathrm{~mm}, 1.0 \mathrm{~mm}$, and $2.0 \mathrm{~mm}$ diameter, and the proportion of steel ratio to GFRP, $10 \%, 30 \%, 50 \%$, and $70 \%$, respectively. Case 1 is a reference case, in which steel was not inserted (i.e., fully GFRP Bars), to compare with Hybrid Bars for verifying the enhancement of tensile performance [7]. In the case 2, $0.5 \mathrm{~mm}$ steel wires were inserted with the steel proportion of $10 \%$ with GFRP becoming D13 bar.

To confirm the tensile performance of FRP Hybrid Bars depending on diameter and proportion of inserted steel wires, various kinds of FRP Hybrid Bars were developed: their manufacturing methods were the same according to the shape of their cross section.

Steel wires are uniformly distributed in the cross section of GFRP to develop the high performance FRP Hybrid Bars. To secure high quality of FRP Hybrid Bars with inserted wires, distribution of the wire in the cross section is important so that guides for fibers and wires (as shown in Figure 2) were prepared in the pultrusion process.

\section{Experiments}

\subsection{Tensile Tests}

Tensile tests were carried out in this study. A total of 81 specimens and 13 cases of FRP Hybrid Bars were tested. Both specimen ends are inserted into a circular steel adapter with grip length of $400 \mathrm{~mm}$ (for D13) and 


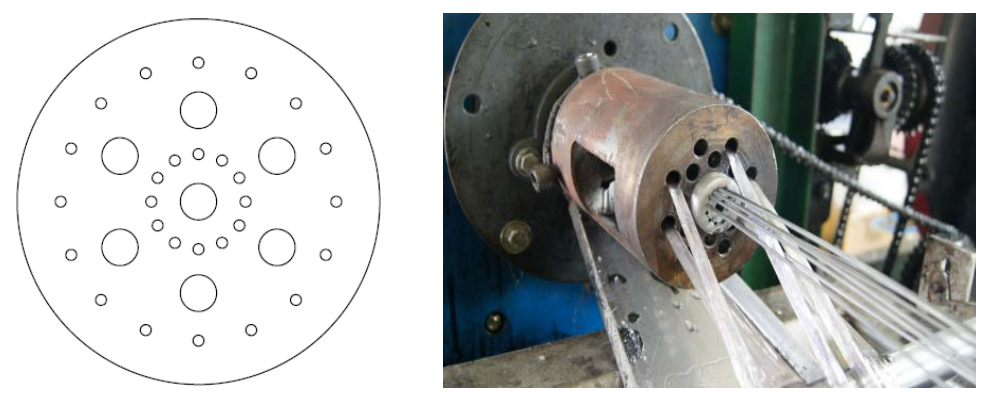

Figure 2. Guides for fibers and wires in pultrusion process.

700 mm (for D16) for tensile test in accordance with ASTM D 3916 [8], mortar was filled into the adapter to use as an anchor.

Figure 3 shows a steel adapter to make specimens of FRP Hybrid Bars for tensile test. To ensure bond strength between the bar and the adapter, small amounts of particles like silica were coated on the surface of the bar. They were then inserted into circular steel adapter, and mortar was filled and cured for a week to obtain the compressive strength at least $60 \mathrm{MPa}$.

Strain gauges were attached at the points of a half and a quarter of the FRP Hybrid Bar, the top and bottom of the specimen were fixed with nuts to be installed at the UTM so that they were not affected by eccentricity. In the experiments, tests were conducted by displacement control with a capacity of $1000 \mathrm{kN}$ UTM and loading rate of $5 \mathrm{~mm} / \mathrm{min}$ [8]. Loading was started with the initial value of $1 \mathrm{kN}$ and then continued until the specimen was failed. Figure 4(a) shows the configuration after completion of specimen, and Figure 4(b) shows how tensile tests were carried out [9].

\subsection{Results and Discussions}

Table 3 shows the results of tensile tests. As results, the improvements of elastic modulus and tensile strength were represented by average values and standard deviations with a sample size of $6-7$. The elastic modulus of FRP Hybrid Bars with inserted wires were improved 20\% - 190\% comparing to the fully FRP Bars, as shown in Table 3. Low elasticity of GFRP was compensated by steel and elastic modulus was improved. Tensile strength was also improved in comparison with the existing fully FRP Bars due to the effects of using a material in high tensile strength (i.e., use of steel wires). The consistent results with relatively low coefficients of variation (CoV, standard deviation over average) are found in this study.

Figure 5 shows the stress-strain curves after calculating the average values of test results for each case. As shown in this figure, it is clear that combination of FRPs and steel improve the elastic modulus and the elastic modulus is increased with increasing the insertion proportion of steel (wires). For an example, steel was mainly dominant in tension until tensile strength reaching $1000 \mathrm{MPa}$ and then FRPs controlled tensile strength in the case of GBSD2-32-D16, as shown in Figure 5. For FRP Hybrid Bars with inserted steel, therefore, abrupt brittleness fracture did not occur when it reached yield strength comparing to the case 1 without steel. This result may explain that high tensile strength of FRPs and high elastic modulus of steel compensated for each other as FRPs and steel were combined.

Figure 6 shows the curves of elastic modulus normalized to steel ratio to GFRP (e.g., elastic modulus $E$ divided by steel volume fraction by cross-section area, $\left.S_{V F}(\%)\right)$ as a function of the diameter of wires by dividing into two cases, D13 and D16. As shown in this figure, the increment of elastic modulus is decreased as increasing the diameter of inserted wires because the attached area is reduced. With the same reason, use of smaller diameter of wire provides higher elastic modulus. Two different materials could be effectively combined, if the area of the attached surface between steel, GFRPs, and resin is fortified. This indicates that tensile performance can be enhanced with increased surface area when steel is combined with GFRP.

Since the tensile performance was verified only in the cases of the diameters of steel wires $0.5 \mathrm{~mm}, 1 \mathrm{~mm}$, and $2 \mathrm{~mm}$ in this study, more cases of prototypes and performance verification are necessary to understand mutual relation of FRP Hybrid Bars depending on the diameter of steel wires.

Figure 7 shows increment tendency in elastic modulus as a function of the steel proportion, in this figure the case of $2 \mathrm{~mm}$ of steel wires inserted into FRP Hybrid Bars was exclusively utilized. This case is divided into two 


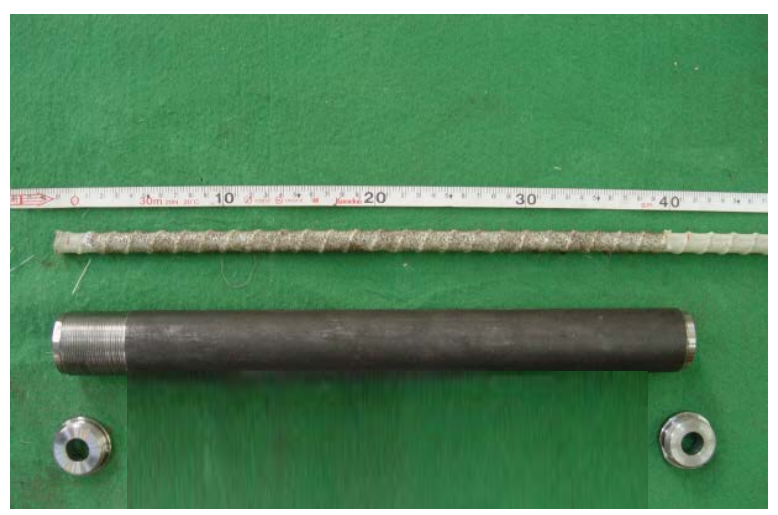

Figure 3. Steel adapter of FRP Hybrid Bars for tensile test.

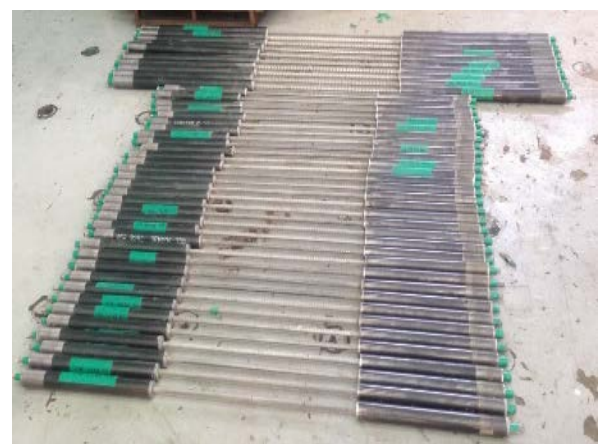

(a)

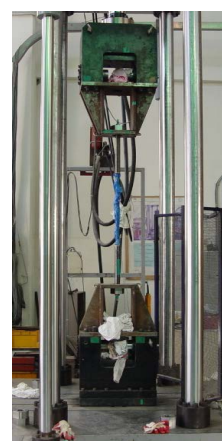

(b)

Figure 4. Tensile test for FRP Hybrid Bar: (a) The specimens after completion of grips (left); (b) Test setup (right).

Table 3. Results of tensile tests.

\begin{tabular}{|c|c|c|c|c|c|c|c|c|}
\hline \multirow[b]{2}{*}{ Case } & \multirow[b]{2}{*}{ Name } & \multirow{2}{*}{$\begin{array}{l}\text { Steel volume } \\
\text { fraction by } \\
\text { cross-section } \\
\text { area (\%) }\end{array}$} & \multicolumn{3}{|c|}{ Elastic modulus, $E$} & \multicolumn{3}{|c|}{ Max. tensile strength, $P$} \\
\hline & & & $\begin{array}{l}\text { Average } \\
(\mathrm{GPa})\end{array}$ & $\begin{array}{l}\text { Improvement } \\
\text { (\%) }\end{array}$ & $\mathrm{CoV}$ & $\begin{array}{l}\text { Average } \\
(\mathrm{MPa})\end{array}$ & $\begin{array}{l}\text { Improvement }^{*} \\
\text { (\%) }\end{array}$ & $\mathrm{CoV}$ \\
\hline 1 & GBN-D13 & None & 51.8 & - & 0.06 & 864.0 & - & 0.06 \\
\hline 2 & GBSD0.5-68-D13 & 10.3 & 67.8 & 30.7 & 0.03 & 1246.1 & 44.2 & 0.02 \\
\hline 3 & GBSD1-17-D13 & 10.6 & 65.6 & 26.6 & 0.04 & 1239.5 & 43.5 & 0.02 \\
\hline 4 & GBSD2-4-D13 & 9.8 & 62.6 & 20.8 & 0.06 & 1224.7 & 41.8 & 0.09 \\
\hline 5 & GBSD2-13-D13 & 31.8 & 88.0 & 69.9 & 0.06 & 1000.7 & 15.8 & 0.06 \\
\hline 6 & GBSD2-21-D13 & 47.1 & 111.3 & 114.8 & 0.07 & 1087.9 & 25.9 & 0.05 \\
\hline 7 & GBSD2-30-D13 & 75.3 & 149.5 & 188.4 & 0.03 & 1092.0 & 26.4 & 0.03 \\
\hline 8 & GBSD0.5-102-D16 & 10.0 & 67.1 & 29.4 & 0.03 & 1278.8 & 48.0 & 0.02 \\
\hline 9 & GBSD1-26-D16 & 10.1 & 62.9 & 21.3 & 0.02 & 1242.9 & 43.9 & 0.04 \\
\hline 10 & GBSD2-6-D16 & 9.3 & 59.8 & 15.4 & 0.06 & 1264.6 & 46.4 & 0.03 \\
\hline 11 & GBSD2-19-D16 & 28.9 & 70.9 & 36.8 & 0.05 & 1212.3 & 40.3 & 0.04 \\
\hline 12 & GBSD2-32-D16 & 48.8 & 101.7 & 96.2 & 0.10 & 1213.4 & 40.4 & 0.05 \\
\hline 13 & GBSD2-45-D16 & 67.1 & 121.3 & 134.0 & 0.08 & 1296.3 & 50.0 & 0.02 \\
\hline
\end{tabular}

"Ralative values to case 1. 

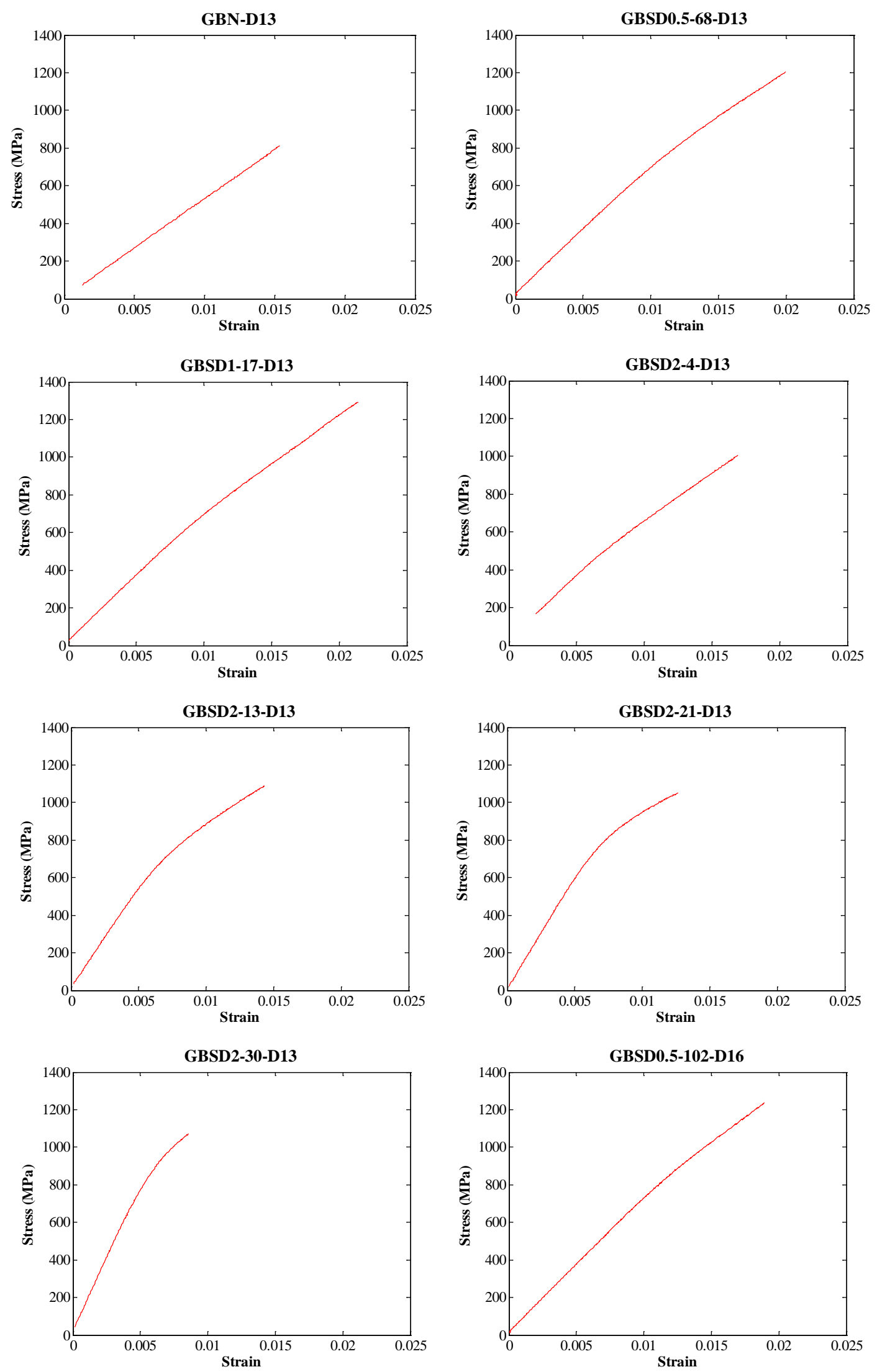

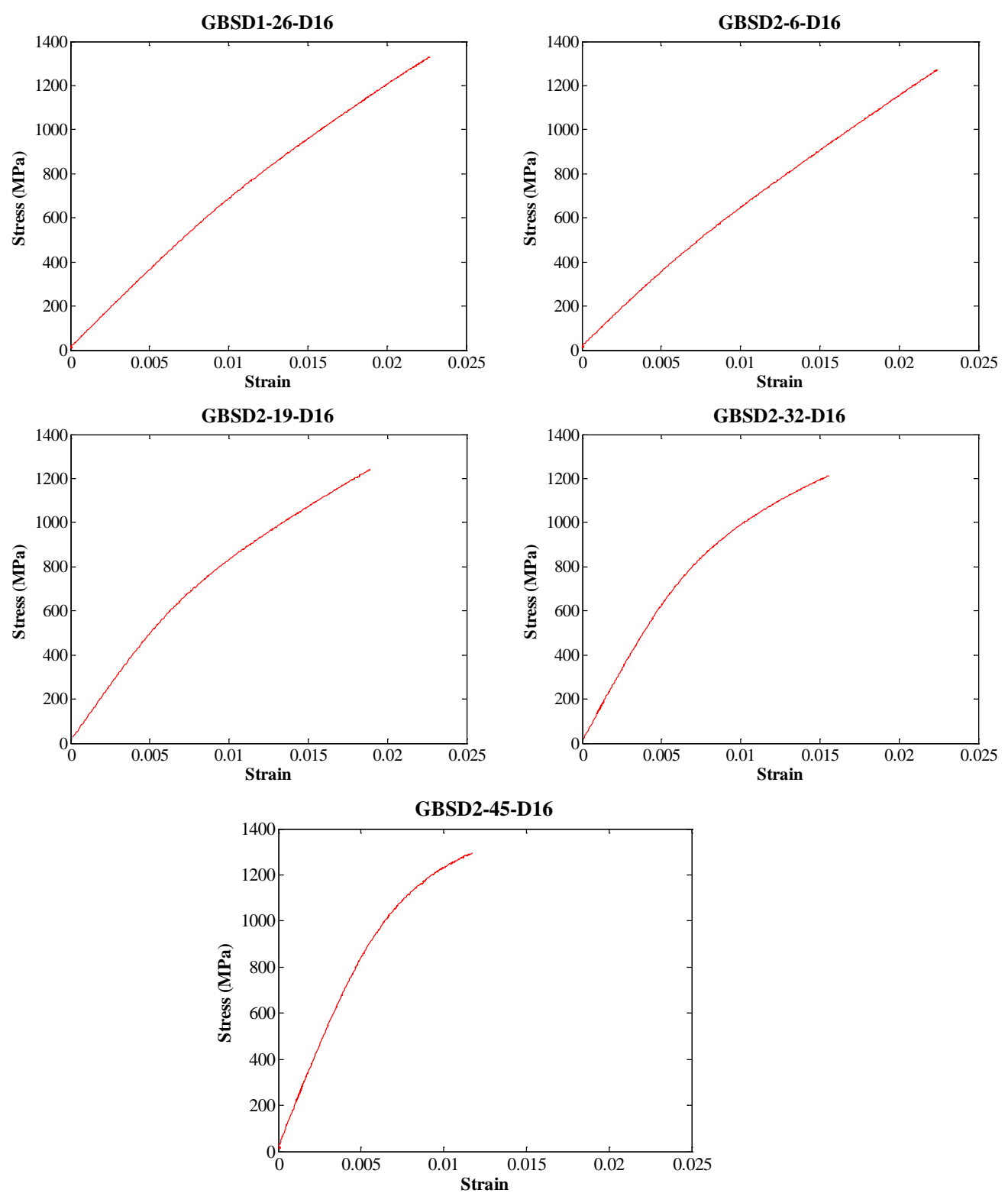

Figure 5. Stress-strain curves for FRP Hybrid Bars.

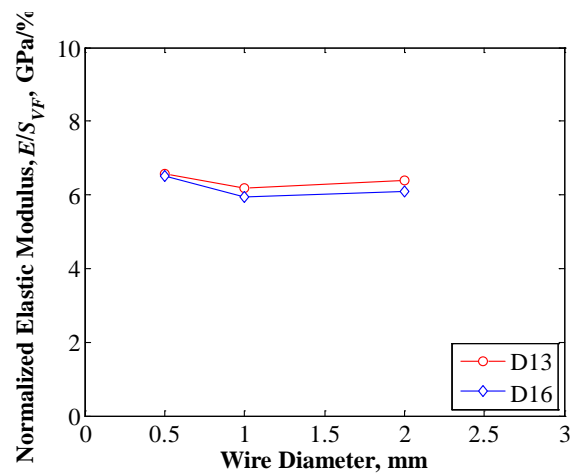

Figure 6. Normalized elastic modulus as a function of the diameter of wires. 


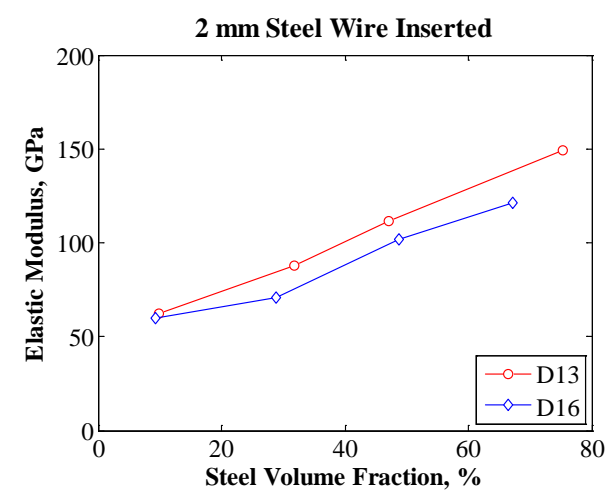

Figure 7. Normalized elastic modulus as a function of steel proportion to GFRP.

cases, D13 and D16. As shown in this figure, the elastic modulus is linearly increased for D13 as the proportion of steel increased from $10 \%$ to $70 \%$, while the increasing slope was a little different for D16. Considering the precision of manufacturing specimens and manufacturing errors in the results of tensile tests, the elastic modulus almost linearly increased as the proportion of steel increased. To obtain optimized proportion of steel, it is necessary to consider several variables, including the economic efficiency according to the proportion of steel.

\section{Conclusions}

In this study, prototypes of FRP Hybrid Bars with inserted steel wires were developed and their tensile performance was verified through tensile tests depending on various variables, such as the proportion and diameter of steel. These FRP Hybrid Bars were designed by dividing into D13 and D16, as an outer diameter, according to the diameter and proportion of inserted wires: GFRPs were combined with steel wires with diameters of $0.5 \mathrm{~mm}$, $1.0 \mathrm{~mm}$, and $2.0 \mathrm{~mm}$ and the proportion of $10 \%, 30 \%, 50 \%$, and $70 \%$, respectively.

As a result of tensile tests, the elastic modulus of FRP Hybrid Bars with inserted wires were improved approximately $20 \%-190 \%$ comparing to the fully GFRP Bars. In addition, the increment in elastic modulus decreased as the diameter of wires increased. Two different materials could be effectively combined, if the area of the attached surface between steel, GFRPs, and resin is fortified.

The elastic modulus of FRP Hybrid Bar is almost linearly increased as a function of the steel proportion inserted into GFRP. To obtain the optimized proportion of steel, it is necessary to consider several variables including economic efficiency according to the proportion of steel.

Brittleness fracture, one of problems of the existing FRPs, was compensated through material hybridization in this study. It can be realized that optimized tensile performance is affected by the diameter and proportion of steel inserted into FRPs significantly. To apply these developed prototypes in marine and harbor structures to replace the steel rebar, it is required to conduct the further studies on various factors, including economic efficiency, practicability of manufacturing process.

\section{Acknowledgements}

This research (2014 Basic Research: Development of Hybrid FRP Bars for Concrete Waterfront Structures) was supported by Korea Institute of Construction Technology and funded by the Ministry of Science, ICT, and Future Planning of Korean Government.

\section{References}

[1] Canadian Society of Civil Engineers (1991) Advanced Composites Materials with Application to Bridges. Canadian Society of Civil Engineers, Montreal.

[2] Kretsis, G.A. (1987) Review of the Tensile, Compressive, Flexural and Shear Properties of Hybrid Fibre-Reinforced Plastics. Composites, 18, 13-23. http://dx.doi.org/10.1016/0010-4361(87)90003-6

[3] Jones, K.D. and DiBenedetto, A.T. (1994) Fiber Fracture in Hybrid Composite Systems. Composites Science and Technology, 51, 53-62. http://dx.doi.org/10.1016/0266-3538(94)90156-2 
[4] Cui, Y. and Tao, J. (2009) A New Type of Ductile Composite Reinforcing Bar with High Tensile Elastic Modulus for Use in Reinforced Concrete Structures. Canadian Journal of Civil Engineering, 36, 672-675. http://dx.doi.org/10.1139/L09-012

[5] Korea Institute of Construction Technology (KICT). www.kict.re.kr

[6] Seo, D.W., Park, K.T., You, Y.J. and Kim, H.Y. (2013) Enhancement in Elastic Modulus of GFRP Bars by Material Hybridization. Engineering, 5, 865-869. http://dx.doi.org/10.4236/eng.2013.511105

[7] Korea Institute of Construction Technology (KICT) (2004) Design and Construction Technology for Concrete Structures Using Advanced Composite Materials: FRP Rebars and Grids (in Korean). Interim Report Submitted to the Korea Research Council of Public Science and Technology.

[8] ASTM. D 3916 (2002) Standard Test Method for Tensile Properties of Pultruded Glass-Fiber-Reinforced Plastic Rods. http://news.cnfrp.net/file_dir/2012-12/20121221100040.pdf

[9] CSA (2002) Test Method for Tensile Properties of FRP Reinforcement. Canadian Standard Association, Mississauga. 